\title{
Analyzing of Drill Stem Test (DST) Result for Dual Porosity Limestone Reservoir
}

\author{
Zheno Kareem Ahmed \\ Petroleum and Energy \\ Technical College of Engineering \\ Sulaimani Polytechnic University \\ Sulaimani, Iraq \\ zheno.ahmed@spu.edu.iq
}

\begin{abstract}
The aim of this paper is to discuss and evaluate the result of DST which was conducted in a limestone reservoir of an oil field at the depth interval 3764.29-3903.0 meter in well-1 to evaluate the dynamic characteristics of the reservoirs, for instance: skin effect, permeability, wellbore storage, reservoir boundary and average reservoir pressure. Reservoir Pressure profiles has been recorded for both Buildup and draw down intervals. Semi-log and log-log coordinates have been used to plot the pressure signature date of both buildup period and its derivative to improve diagnostic and Horner plot. In addition, a dual porosity reservoir and infinite acting characteristic was discovered as a result of the well test data interpretation. Wellbore storage, skin factor and transient flow effects have been detected in the DST analysis on the dual porosity behavior due to phase re distribution. Using final buildup sections, the flow parameters of dual porosity reservoir were determined as the flow between fissure and matrix was $\left(7.558 \times 10^{-}\right.$ $\left.{ }^{6}\right)$ while, the storability ratio between fissure and matrix was calculated as 0.3 and permeability is $102 \mathrm{MD}$ for both matrix and the fissure together. However, negative value of skin factor mostly appears in double porosity limestone reservoirs, positive skin factor of the reservoir has been observed in this study. It can be considered that the positive skin factor can be resulted in either the formation was partially penetrated and /or wells were not cleaned up properly.
\end{abstract}

Keywords: DST, dual porosity, wellbore storage, average reservoir pressure, storability ratio, skin factor.

\section{INTRODUCTION}

Well testing has always been introduced as the most exciting part of petroleum industry because it can aid engineers to have a direct contact with reservoirs. However, it is also an area where engineers can face major challenges [4].

It is revealed by [5] that when a well is tested, it is required to monitor the response of the reservoir in order to improve its production (or injection) conditions. The response, which allows us to draw conclusions about the condition of the reservoir, always depends on the characteristics and properties of the reservoir. The interpretation of various types of well tests is done by the engineers whose judgment is based on geological, petrophysical and reservoir engineering data.

Engineers use number of well testing methods including buildup, drawdown, injection test, falloff test, interference test, Wireline formation test and drill steam (pressure transient) test to acquire a quantitative analysis

\author{
Halkawt Ismail M-Amin \\ Accounting \\ Dukan Technical Institute \\ Sulaimani Polytechnic University \\ Sulaimani-Iraq \\ halkawt.amin@spu.edu.iq
}

of reservoir properties [8]. These tests are usually conducted by using special tool to create pressure disturbance in reservoir and then recording the pressure response at the wellbore, i.e., bottom hole flowing pressure $\left(\mathrm{p}_{\mathrm{wf}}\right)$, as a function of time [17].

Moreover, it has been experienced by [1] and [4] that during well testing the main three components which are measured at different time are: a) Wellbore storage effect that is detected at early times due to well completion operation, b) Reservoir dynamic behaviors almost through middle time and c) Boundary effect could be measured at late time and then by combining and evaluating these components, individual dynamic behaviors of reservoirs can be analyzed by using different types of plots and software analysis.

Therefore, it is mentioned by [11] and [13] that the main objectives of well testing are: i) Reservoir evaluation: in order to make a decision about the optimal production of a reservoir or to determine whether it is worth to invest it or not, reservoirs' deliverability and its' size needs to be known. Moreover, the reservoir conductivity (kh), the initial reservoir pressure, and the reservoir limits (or boundaries) are the most important measures to evaluate reservoir by applying well testing. ii) Reservoir management: all through the life of a reservoir, the performance and well condition must continually be monitored. It is a good idea to monitor changes in average reservoir pressure because in this way more accurate predictions can be made for future reservoir's performance. iii) Reservoir description: geological formations in terms of faults, barriers, reservoir heterogeneity and fluid fronts of hosting oil, gas and water can be identified with the help of stratigraphy.

In this paper drill stem test has been introduced and the result of it applied to obtain the aims of well testing.

Drill Stem Test (DST) has been described by [3] and [18] as a tool of well testing to evaluate the dynamic characteristics of oil or gas reservoirs, for instance: skin effect, permeability, wellbore storage, reservoir boundary and average reservoir pressure. The impact of average reservoir pressure and wellbore storage is an aid to predict the flowing phase from the oil or gas bearing formation into the wellbore. A detailed description of DST tool is presented in the following section. 


\section{LITERATURE REVIEW}

In this section a review of DST and some parameters which are analyzed by it are reviewed based on literature review.

\subsection{Description of DST tool}

This form of testing has been used for formation evaluation for many years. In a DST testing there is a special tool mounted on the end of the drill string as shown in figures $1 \& 2$ sketched and real figures, respectively. This is normally used to test a newly drilled well, since it can only be carried out while a rig is over the hole but sometimes it can be used in productive zones in the development wells. As DST tools are designed for various operating environments they are of multiuse. It means that they can be redressed between runs, while permanent completion components are designed for specific installations and long life [11]. Drill stem testing tools usually include two or more recording pressure gauges, one or two packers, and a set of flow valves [4]. A DST tool is attached to the end of the drill string and run into the mud-filled wellbore, the zone to be tested. The packers help to isolate the formation from the mud column in the annulus while the valves on the DST device allow engineers to have a sequence of flow periods followed by shut-in periods. By having pressure gage recorder on the DST device, pressure can be recorded during the flow and shut in period. It is also important to design the Bottom Hole Assembly (BHA) and DST string based on the criteria of burst load, collapse load and shear failure in order to have a proper and safe DST operating condition [3] and [18].

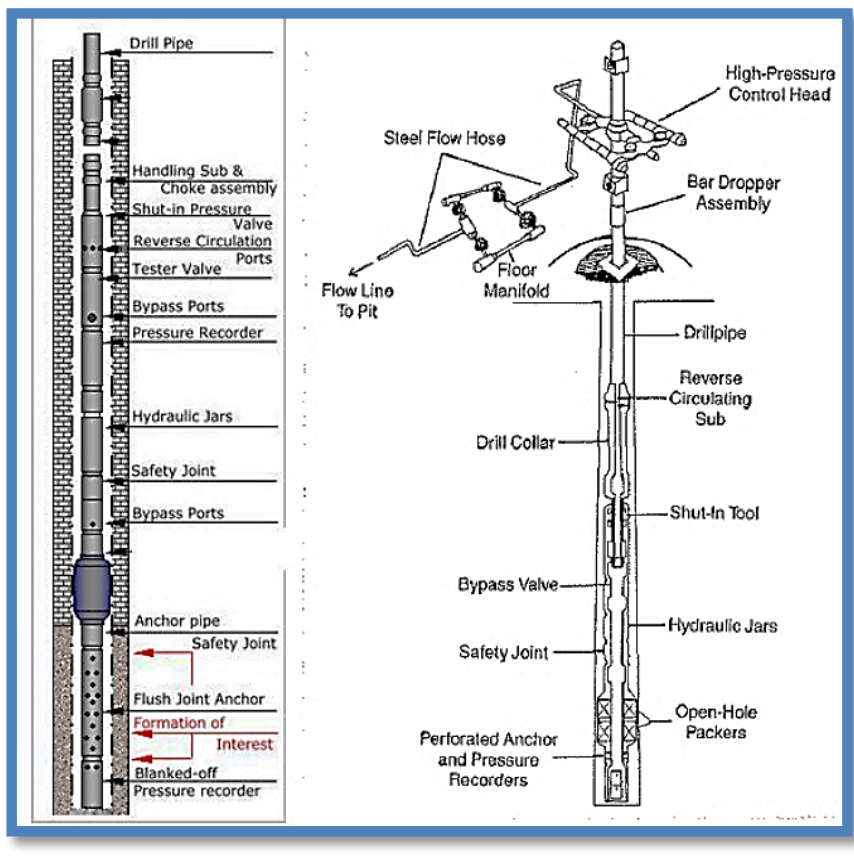

Figure 1: sketched DST string and BHA for DST operation [4].

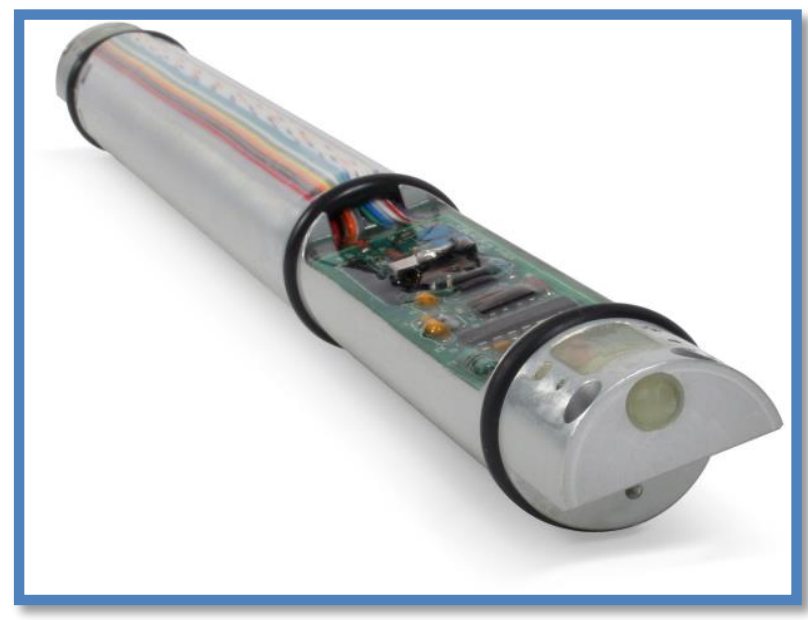

Figure 2: real DST string and BHA for DST operation [6].

\subsection{The objectives of well testing by the Drill Stem}

A good DST yields a sample of the type of reservoir fluid present, it also indicates the flow rates, and it enables us to conduct a measurement of static and flowing bottom-hole pressure and a short term pressure transient test. With the help of DST we can determine the possibility of commercial production judging by the types of fluids recovered and the flow rates observed. We can also estimate the formation properties as well as the well bore damage analyzing the pressure data [3].

It also allows us to estimate the flow potential of a well with a regular completion that uses stimulation techniques to remove damage and increase effective wellbore size. The test also helps us estimate data such as formation permeability, skin factor and static reservoir pressure and is able to tell us the type of fluids the well will produce if it is completed in the tested formation [7].

\subsection{Procedure for running a conventional drill stem test}

When the tester valve is open the formation fluid can flow into the drill pipe. During the flow period when liquid level does not reach the surface the DST test typically displays a decreasing flow rate and when the tester valve is closed for a buildup period, the wellbore storage coefficient decreases by as much as two orders of magnitude. Pressure is recorded throughout the whole test but the pressure data recorded during the shut-in period can be particularly valuable for estimating formation characteristic such as permeability/thickness product and skin factor and for determining possible pressure depletion during the test [11] and [4].

\subsection{Flow periods in DST test}

Generally a DST test is made up of two flow periods and two shut-in periods. The initial flow period is a quite short production period, which does not last more than 10 minutes and the main aim here is to draw down the pressure slightly near the well bore permitting any mudfiltrate invaded zone to bleed back to or below static reservoir pressure [18]. 
It is the initial shut-in period when the pressure builds back to true static formation pressure. If it takes long enough and wellbore storage effects can end, some build up data for initial estimates of reservoir properties can be taken in that time [[12].

In the final flow period we can capture a large sample of formation fluid and draw down the pressure as far out into the formation as possible to see beyond any near wellbore damage.

In the final shut-in period it is possible to obtain good pressure buildup data so that formation properties can be estimated. If we compare the final (or extrapolated) pressure from the second shut-in period to the initial shut-in pressure we can see if pressure depletion has occurred during the DST which indicates that the well has been tested in a small, non-commercial reservoir. The final shut in period can be as long as the second flow period (for high permeability formations) or even twice long (for low-permeability formations).

Figure 3 shows a typical pressure chart from an older mechanical gauge although show electronic gauges are more frequent these days. The data were recorded during a dual flow, dual shut-in DST [12] and [18].

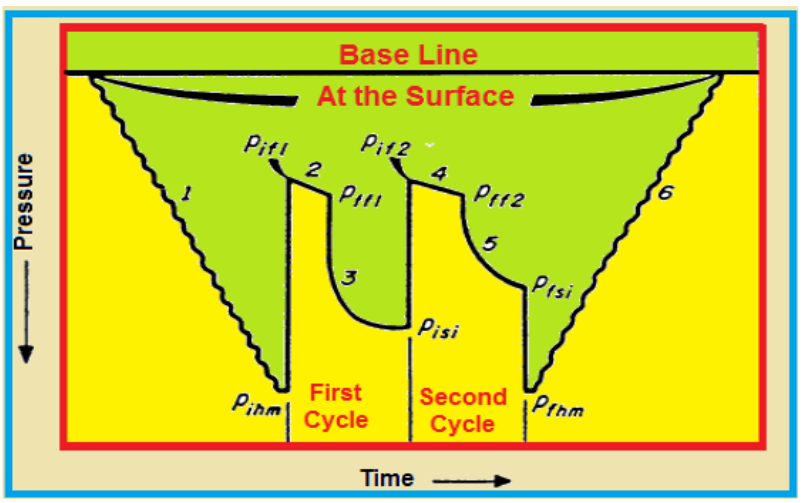

Figure 3: Typical drill stem test (DST) pressure chart [5].

\subsection{Measured parameters by DST tool}

There are number of parameters and reservoir characteristics which are analyzed in this paper need to be reviewed here:

\section{1) Wellbore Storage Effect:}

Opening the well at surface, the first flow that will come out at well head is due to the expansion of wellbore fluid alone. When the reservoir fluid starts to contribute to the production the expansion continues until the sand face flow rate equals the surface flow rate (when expressed at the same conditions) [5].

2) Radius of Investigation:

Sometimes it is necessary to investigate the area around the well or to determine the distance a pressure transient has reached. The distance, which is reached by the pressure disturbance or a transient during a given time, is called the radius of investigation, $r_{\text {inv }}$ [4].

\section{3) The Skin Effect:}

Due to local heterogeneities pressure transmission does not take place uniformly throughout the reservoir. These heterogeneities do not affect the pressure change within the well, with the exception of those that take place in the immediate vicinity of the wellbore. However, it often happens that a zone develops around the well which is invaded by mud filtrate or cement during the drilling or completion of the well. If this zone has a lower permeability than the reservoir, it will act as a skin around the wellbore causing higher pressure drop [14].

\section{4) Flow Efficiency:}

Flow efficiency is very often used to describe the wellbore damage. This is basically the ratio of the theoretical pressure drop with no skin present to the actual pressure drop measured during the test [6].

\section{5) Partial Penetration Skin:}

Wellbore damage is not the only reason for the development of skin effect. Actually, if a well has limited entry, or it only partially penetrates the formation, it means that flow cannot enter the well during the whole production period and there will be a more significant pressure drop in the flow rate than in case of a well that fully penetrates the formation. That is when it can be expected about partial penetration skin effect. In case of partial penetration of a well into a producing formation an important factor is the ratio of vertical to horizontal permeability. Furthermore, having shale streaks or tight layers in the tested interval result in the effective vertical permeability is small, and then the well will tend to behave as the formation thickness is equal to the completion thickness. On the other hand, if the vertical permeability is high, it means that the effect of partial penetration will be high and an extra pressure drop near the well can be occurred [14] and [15].

\section{6) Dual Porosity Reservoirs}

Double porosity models are applicable when the reservoir is heterogeneous and consist of rock matrix blocks with high storativity and low permeability, which is connected to the well by natural fissures of low storativity and high permeability as shown in figure 4 [2] and [7]. The reservoir fluid is mostly stored in the matrix blocks porosity, the fissure network storage accounts for only a small fraction of the reservoir storage [8].The matrix blocks cannot flow to the well directly, even though most of the hydrocarbon is stored in the matrix blocks, it has to enter the fissure system in order to be produced (Bath 1998). Therefore, this phenomenon has to be calculated with two responses pressure line in case of the pressure transients (dual porosity media). In reservoirs with distinct primary and secondary porosity the heterogeneity is noticeable in pressure transients. These pressure effects are known as double porosity or dual porosity behavior, and are quite common in naturally fractured reservoirs [17].

Compared to the homogeneous model there are two extra variables in the dual porosity model. One of them is the storativity ratio $(\omega)$, which defines the contribution of the fissure system to the total storativity. Usual values for this ratio $(\omega)$ are in the order of $10^{-1}$ for multiplelayer systems down to $10^{-2}$ or $10^{-3}$ for fissured ones, but the fissures provide only a fraction of the total storativity. 


$$
\omega=\frac{\varphi_{f} C_{t f}}{\varphi_{f} C_{t f}+\varphi_{m} C_{t m}}
$$

The second variable is called interporosity flow coefficient $(\lambda)$ which is the fluid exchange between the two media (the matrix and fractures) constituting a dual porosity system.

$$
\lambda=a \frac{k_{m}}{k_{f}} r_{w}^{2}
$$

Where $\mathrm{km}$ is the permeability of the matrix, $k_{f}$ is the permeability of the natural fractures, and $\alpha$ is the parameter characteristic of the system geometry.

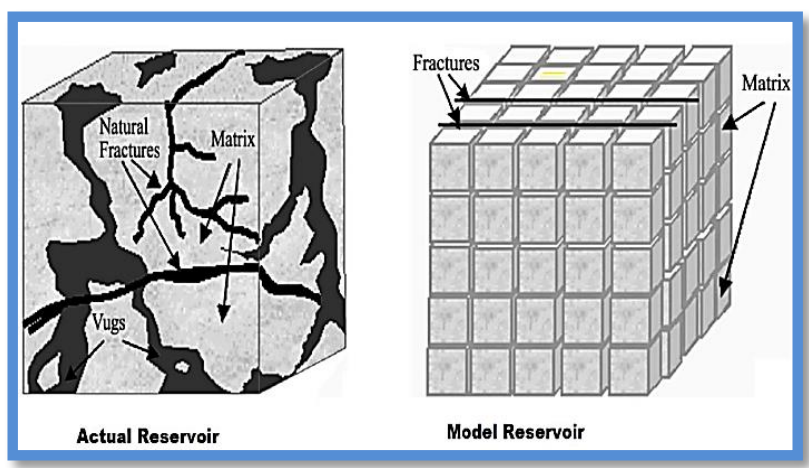

Figure 4: actual and idealized dual- porosity reservoir model [12].

\section{METHOD AND MATERIALS}

In this work, Windows based Pan System 3.5 has been applied, this software facilitates the preparation and edition of well test data analysis, then plotting the data and editing sections of the plotted data. Data of well can be analyzed and a final report can be created for the input data and results of the analysis.

DST was carried out to obtain more precise information concerning the content of the formation, to take representative samples and finally to obtain the reservoir and well performance parameters (pressure, temperature, permeability, skin, boundary, etc.).The test started on 14th December in 2013 at 7.00 PM on a limestone reservoir on well-1 and finished on $29^{\text {th }}$ December at 12.00 PM.As the data was recorded in field units, field units is also used in this paper. The general well information, well structure, test sequence and events and initial well test data are shown in the following tables:

Table 1: General well-1 Information

\begin{tabular}{|l|l|}
\hline Classification: & Appraisal well \\
\hline Total depth: & $3903 \mathrm{~m}$ MD (TVD: $3903.0 \mathrm{~m})$ \\
\hline Ground Elevation & $566.15 \mathrm{~m}$ above sea level \\
\hline $\begin{array}{l}\text { Rotary Kelly bushing } \\
\text { Elevation }\end{array}$ & $\begin{array}{l}1578.33 \mathrm{~m}(\text { where Rotary Table } \\
\text { Height: } 12.18 \mathrm{~m})\end{array}$ \\
\hline Deviation & $3728-3738 \mathrm{~m}$ Inclination: $3.25^{\circ}$ \\
\hline
\end{tabular}

Table 2: Well-1 Structure

\begin{tabular}{|l|l|l|l|}
\hline $\begin{array}{l}\text { Casing, } \\
\text { Cementing }\end{array}$ & $36 "$ & $0-27 \mathrm{~m}$ & Conductor pipe \\
\hline
\end{tabular}

\begin{tabular}{|l|l|l|l|}
\hline & $26^{\prime \prime}$ & $0-438.0 \mathrm{~m}$ & $\begin{array}{l}\text { Tope of cement: } \\
\text { on surface }\end{array}$ \\
\hline & $20^{\prime \prime}$ & $0-1995.44 \mathrm{~m}$ & $\begin{array}{l}\text { Tope of cement: } \\
\text { on surface }\end{array}$ \\
\hline & $\begin{array}{l}16^{\prime \prime} \\
\text { liner }\end{array}$ & $\begin{array}{l}1938.15-2515.0 \\
\mathrm{~m}\end{array}$ & $\begin{array}{l}\text { Tope of cement: } \\
\text { on surface }\end{array}$ \\
\hline & $\begin{array}{l}13 \\
3 / 8^{\prime \prime}\end{array}$ & $0-3764.3 \mathrm{~m}$ & $\begin{array}{l}\text { Tope of cement: } \\
1600 \mathrm{~m}\end{array}$ \\
\hline Open hole: & $12^{1 / 4^{\prime \prime}}$ & $3764.3-3903.0 \mathrm{~m}$ & \\
\hline
\end{tabular}

Table 3: Test Sequence and events

\begin{tabular}{|l|l|}
\hline Type of test & Duration time \\
\hline $\begin{array}{l}\text { Pressure Static } \\
\text { Recovery (PSR) phase }\end{array}$ & $17.12 .201318^{50}-18.12 .201317^{45}$ \\
\hline Initial flow period & $18.12 .201317^{45}-18.12 .201319^{45}$ \\
\hline Initial Build up & $18.12 .201317^{45}-19.12 .201308^{20}$ \\
\hline $\begin{array}{l}\text { Artificial lifting second } \\
\text { flow period }\end{array}$ & $19.12 .201308^{20}-20.20 .201318^{25}$ \\
\hline Clean Up Period & $20.12 .201318^{20}-21.12 .201318^{00}$ \\
\hline Bottom Hole Sampling & $21.12 .201318^{00}-23.12 .201321^{45}$ \\
\hline Capacity Test & $23.12 .201321^{45}-25.12 .201311^{45}$ \\
\hline Final Build up & $25.12 .201311^{45}-29.12 .201311^{45}$ \\
\hline
\end{tabular}

\begin{tabular}{|c|c|}
\hline Open interval & $\begin{array}{l}3764.29-3903.0 \quad \mathrm{~m} \\
\text { (TVD):3764.29-3903m }\end{array}$ \\
\hline Formation, lithology & 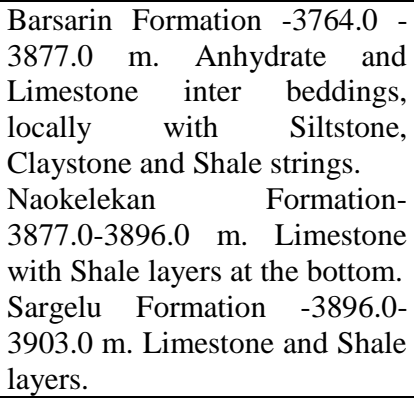 \\
\hline Losses in this section & 885 Barrels \\
\hline $\begin{array}{ll}\begin{array}{l}\text { Expected } \\
\text { pressure }\end{array} & \text { formation } \\
\end{array}$ & Hydrostatic \\
\hline $\begin{array}{l}\text { Expected formation } \\
\text { temperature }\end{array}$ & $95.3^{\circ} \mathrm{C}$ at $2743 \mathrm{~m} \mathrm{MD}$ \\
\hline Mud type, weight & $\begin{array}{l}\mathrm{KCl} / \mathrm{PHPA} \text { Polymer mud / } 9.7 \\
\text { ppg }\end{array}$ \\
\hline Expected $\mathrm{CO}_{2}$ & Max. $45000 \mathrm{ppm}$ \\
\hline Expected $\mathrm{H}_{2} \mathrm{~S}$ & Max. $270000 \mathrm{ppm}$ \\
\hline Expected formation fluid: & Oil, water \\
\hline 3 1/2" BTS-6 tubing: & $\begin{array}{l}12.95 \text { ppf, BTS6, ID: 2.75", } \\
\text { Capacity: } 3.83 \mathrm{l} / \mathrm{m}\end{array}$ \\
\hline $81 / 4$ " DC: & $\begin{array}{l}\text { 160.3 ppf, ID: } 213 / 16 " 4.01 \\
1 / \mathrm{m}\end{array}$ \\
\hline DST Cushion Type: & Fresh clean water, $\mathrm{SG}=1$ \\
\hline Packer setting depth: & $3730.42 \mathrm{~m} \mathrm{MD}$ \\
\hline Volume below the packer: & 184.04 barrels \\
\hline TV depth: & $\begin{array}{l}3716.38 \mathrm{~m} \mathrm{MD(TVD:} 3716.38 \\
\mathrm{~m})\end{array}$ \\
\hline Cushion length: & $2716.0 \mathrm{~m}$ \\
\hline Cushion level: & $1000.0 \mathrm{~m}$ \\
\hline Cushion volume: & 58.81 barrels \\
\hline $\begin{array}{l}\text { Cushion hydr. pressure at } \\
\text { TV depth: }\end{array}$ & $3843.8 \mathrm{psi}$ \\
\hline Formation pressure at TV & $5257.64 \mathrm{psi}$ \\
\hline
\end{tabular}

Table 4: Initial well test data 


\begin{tabular}{|l|l|}
\hline depth: & \\
\hline $\begin{array}{l}\text { Annular fluid hyd. } \\
\text { pressure at TV depth: }\end{array}$ & $6146.01 \mathrm{psi}$ \\
\hline Initial depression: & $1413.8 \mathrm{psi}$ \\
\hline
\end{tabular}

Figure 5 and table 4 illustrates the measured bottom hole pressure $\left(\mathrm{P}_{\mathrm{wf}}\right)$ and the liquid rate during the entire well test. The figure also shows the events that happened during the DST test, which seemingly was not a conventional procedure as in certain periods the operation was stopped due to the technical issues.

After the Initial buildup nitrogen was injected into the well to reduce the cushion so that the well could start to flow. In the cleaning period we can see that different choke sizes were used and immediately after this bottom hole samples were taken. This production period was followed by the capacity test in which the 32/64 "inch, 40/64" and 48/64 inch choke sizes were used and the PVT samples were taken from separator.

The final buildup was conducted for four days. During the PSR period the pressure change does not have a significant effect and the difference between the wellbore and the formation pressure was very high (approximately $900 \mathrm{psi}$ ). The production depression on 48/64" choke was around 825 psi. This significant depression was caused mainly by the skin effect.
Table 4: data including recorded pressure, time and flow rate from figure 5 during the well test.

\begin{tabular}{|c|c|c|}
\hline $\begin{array}{c}\text { Time } \\
\text { (hour) }\end{array}$ & $\begin{array}{c}\text { Pressure } \\
\text { (Psi) }\end{array}$ & $\begin{array}{c}\text { Flow rate } \\
\text { (STbL/day) }\end{array}$ \\
\hline 91.730 & 6274.86 & 0 \\
\hline 113.66 & 5372.31 & -1 \\
\hline 115.76 & 5284.81 & 20 \\
\hline 128.33 & 5323.72 & 0 \\
\hline 162.63 & 5348.68 & 150 \\
\hline 170.33 & 5259.58 & 670 \\
\hline 171.56 & 5353.20 & 0 \\
\hline 181.09 & 5204.18 & 470 \\
\hline 183.00 & 4846.17 & 1150 \\
\hline 186.05 & 4731.62 & 1570 \\
\hline 189.31 & 5125.50 & 1280 \\
\hline 191.18 & 5185.56 & 470 \\
\hline 197.09 & 5325.48 & 150 \\
\hline 203.10 & 4737.94 & 1820 \\
\hline 205.59 & 4837.99 & 1280 \\
\hline 207.69 & 4957.38 & 970 \\
\hline 215.08 & 6264.69 & 300 \\
\hline 237.73 & 5094.65 & 700 \\
\hline 251.08 & 4698.63 & 1507 \\
\hline 262.38 & 4628.05 & 1740 \\
\hline 276.06 & 4544.02 & 1900 \\
\hline 372.61 & 5367.76 & 0 \\
\hline & & \\
\hline
\end{tabular}

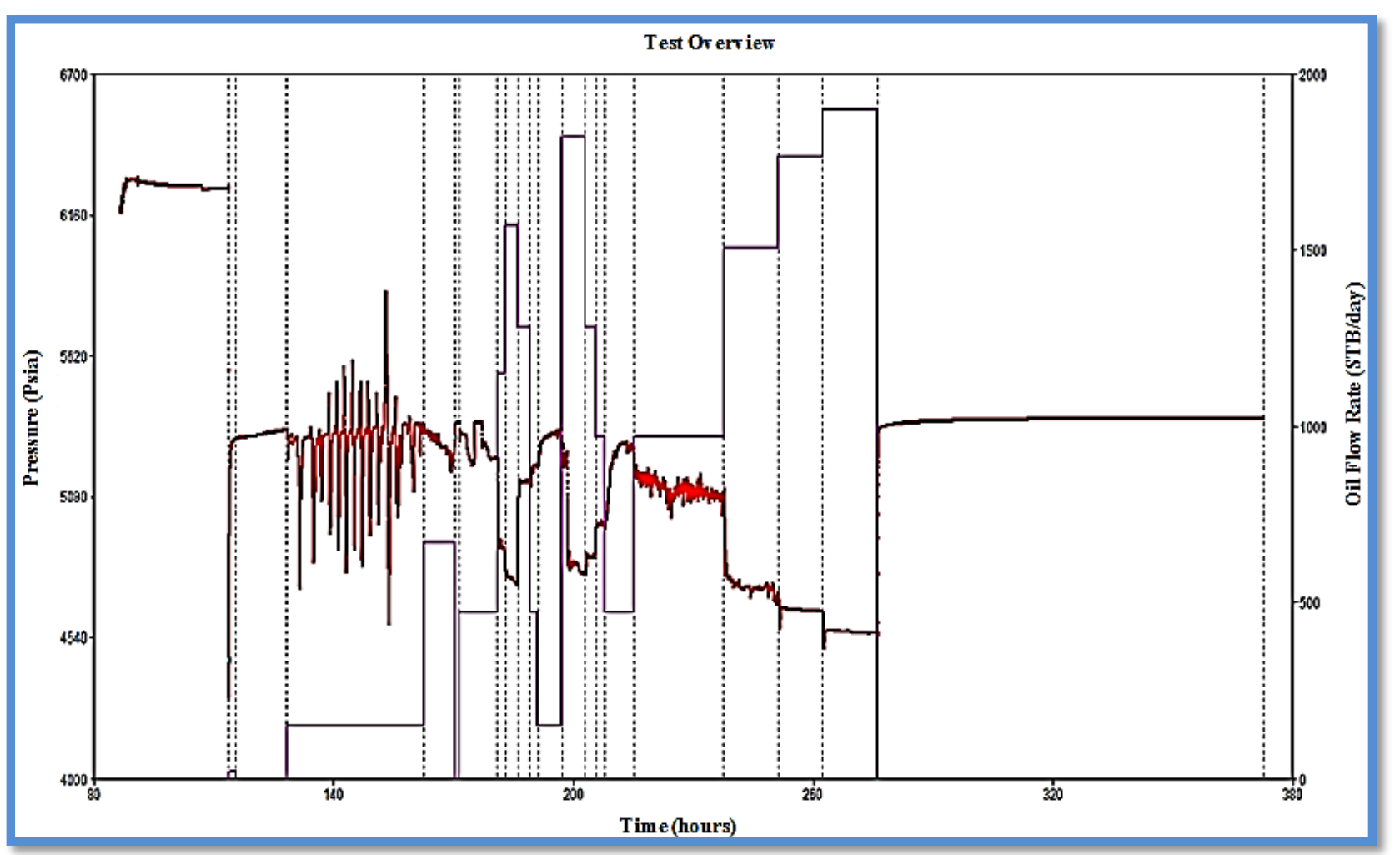

Figure 5: Flow rate change, pressure change versus time of the test 


\section{RESULTS}

\subsection{Buildup curves interpretation:}

The geological information of the tested interval revealed a fractured limestone reservoir. During the analysis the best results could be obtained by the dual porosity model. It showed transient flow conditions during the early and later production periods. The dual porosity shows a pseudo steady state model in most cases as it was supported by the literature and the industrial experience as well as the pressure curve evaluation. The calculations also confirm that the best model for flow model is dual porosity (pseudo steady state). It can be seen from the following figures that there are two buildup pressure sections, but because initial buildup was continuously affected by phase segregation as shown in figure 6 , its data cannot totally be used for interpretation. Despite being affected by

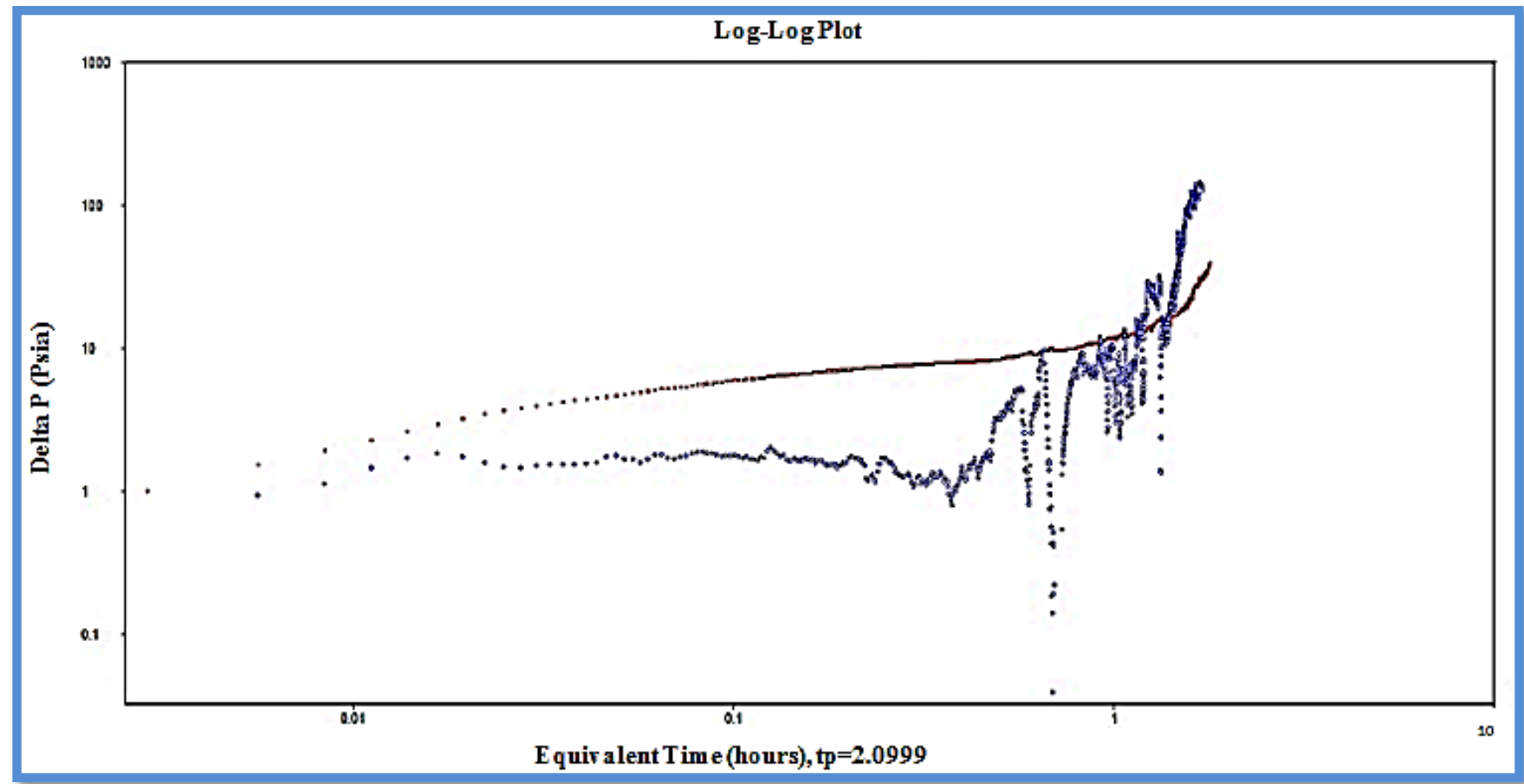

Figure 6: $\log$-Log plot for initial buildup -well-1

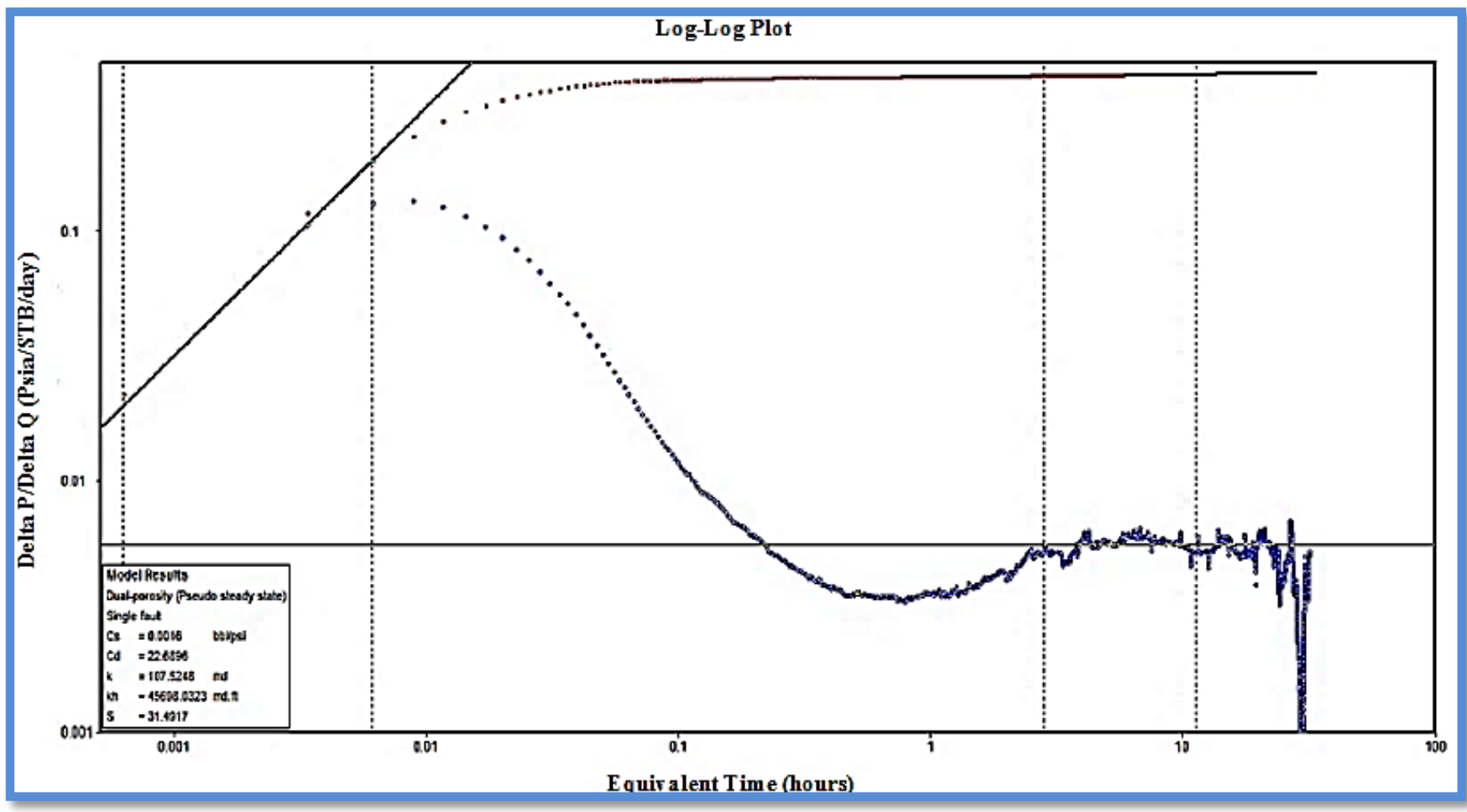

Figure 7: Log- Log diagnostic plot for final buildup well-1 
wellbore storage. the plots of final buildup pressure result can be interpreted. Figure 7 shows a Log- Log diagnostic plot for the final buildup well-1.

Table 5: Results of Log - Log diagnostic plot for final buildup

\begin{tabular}{|c|c|c|}
\multicolumn{3}{|c}{ for well-1 } \\
\hline $\begin{array}{c}\text { Well bore storage } \\
\text { Horizontal Permeability, } \\
\left(\mathrm{kh}_{\mathrm{h}}\right)\end{array}$ & 0.0016 & $\mathrm{bbl} / \mathrm{day}$ \\
\hline $\begin{array}{c}\text { Wellbore Storage } \\
\text { Coefficient, }\left(\mathrm{C}_{\mathrm{s}}\right)\end{array}$ & 22.6896 & $\mathrm{mD}$ \\
\hline $\begin{array}{c}\text { Permeability thickness, } \\
(\text { kh*heff })\end{array}$ & 45698.0323 & $\mathrm{mD}^{*} \mathrm{ft}$ \\
\hline Skin Factor & 31.4917 & - \\
\hline
\end{tabular}

Dual porosity on a derivative plot mostly appears as two regions of radial flow with the same conductivity, $\mathrm{k}_{\mathrm{h}}$, separated by a transition period called the dual porosity dip. However, in figure 7 , it can clearly be understood that fracture radial flow is completely hidden by the wellbore storage effect at early time region. At the same time the transition to system flow and the matrix and fracture system radial flow can be seen clearly in the middle time region.

Due to the effect of dispersion on the late time regime in response of derivative pressure curve, two reservoir analysis models have been applied in this evaluation:

- Wellbore storage mode: constant wellbore storage \& skin.

- Flow model: dual porosity (pseudosteady state).

- Reservoir boundary model: a constant pressure (aquifer) boundary.
This flow model has a dual porosity configuration with a transient interporosity flow. For boundary model there is one constant pressure boundary. The distance L1 is measured from the well to the fault on the basis of being perpendicular to the boundary. Table 5 shows the results obtained in figure $7(\log -\log$ diagnostic plot for final buildup well-1).

In both Log-Log plot and semi-Log plot, equivalent time has been applied for Log -Log and Horner for semi-log as a time axis and full history, which takes into account the entire previous history of the production wells. Figure 8 shows semi-Log diagnostic plot for the final buildup well-1. The fracture and matrix radial flow can be seen as a straight line that describes radial flow of the fissure and matrix together.

Table 6 shows the result of calculations obtained from figure 8 Semi-Log diagnostic plot for the initial buildup well1. The pressure is considered to be extrapolated and the initial pressure of the reservoir is shown as well.

Table 6: Results of Semi-Log diagnostic plot for final buildup

\begin{tabular}{|l|c|c|}
\hline Horizontal Permeability, $\left(\mathrm{k}_{\mathrm{h}}\right)$ & 105.1993 & $\mathrm{mD}$ \\
\hline Permeability thickness, $(\mathrm{kh} * \mathrm{heff})$ & 44709.7122 & $\mathrm{mD} / \mathrm{ft}$ \\
\hline Calculated formation pressure, $\left(\mathrm{P}_{\mathrm{i}}\right)$ & 5389.5798 & $\mathrm{psia}$ \\
\hline Radius of investigation, ( $\left.\mathrm{r}_{\text {inv }}\right)$ & $>254.4819$ & $\mathrm{ft}$ \\
\hline $\begin{array}{l}\text { Pressure loss due to total Skin, } \\
\left(\Delta \mathrm{P}_{\text {spr }}\right)\end{array}$ & 659.7814 & $\mathrm{psi}$ \\
\hline Skin factor & 30.6724 & - \\
\hline
\end{tabular}

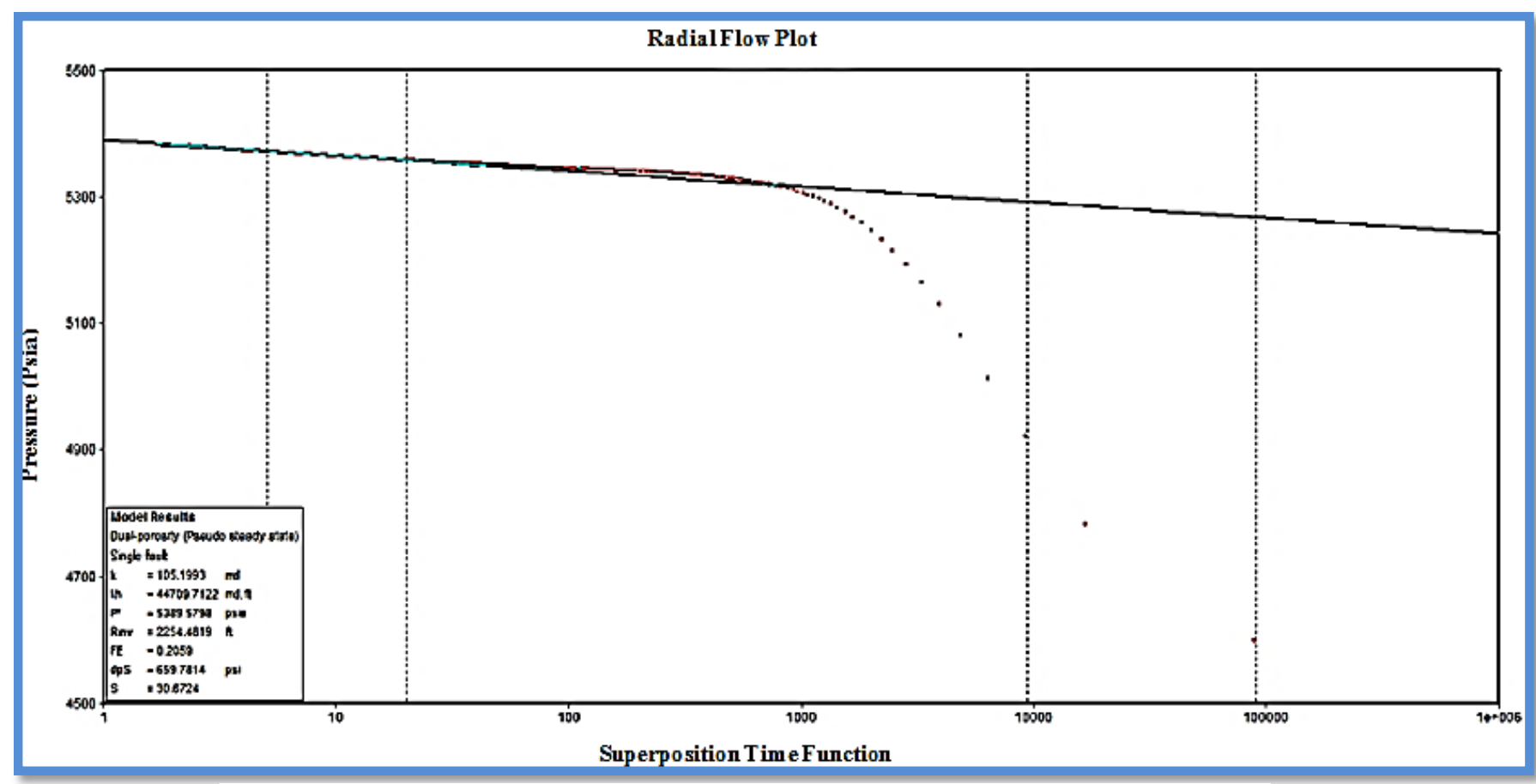

Figure 8: Semi-Log diagnostic plot for the final buildup well-1 
By using line fitting, as well as history matching, a reasonable match was achieved in Log-Log and semi-log plots in figure 9 and figure 10, respectively. The result of matching final buildup well-1 for the first reservoir model listed in table 7.

The Log-Log curve, figure 9, shows that the measured and the calculated pressure fit together, except for the last few highly disturbed measuring points.
Figure 10 shows matched Semi-Log curves, and as it can obviously be realized that the calculated pressures excellently fit the measured pressure points. The entire measurement range fits together properly.

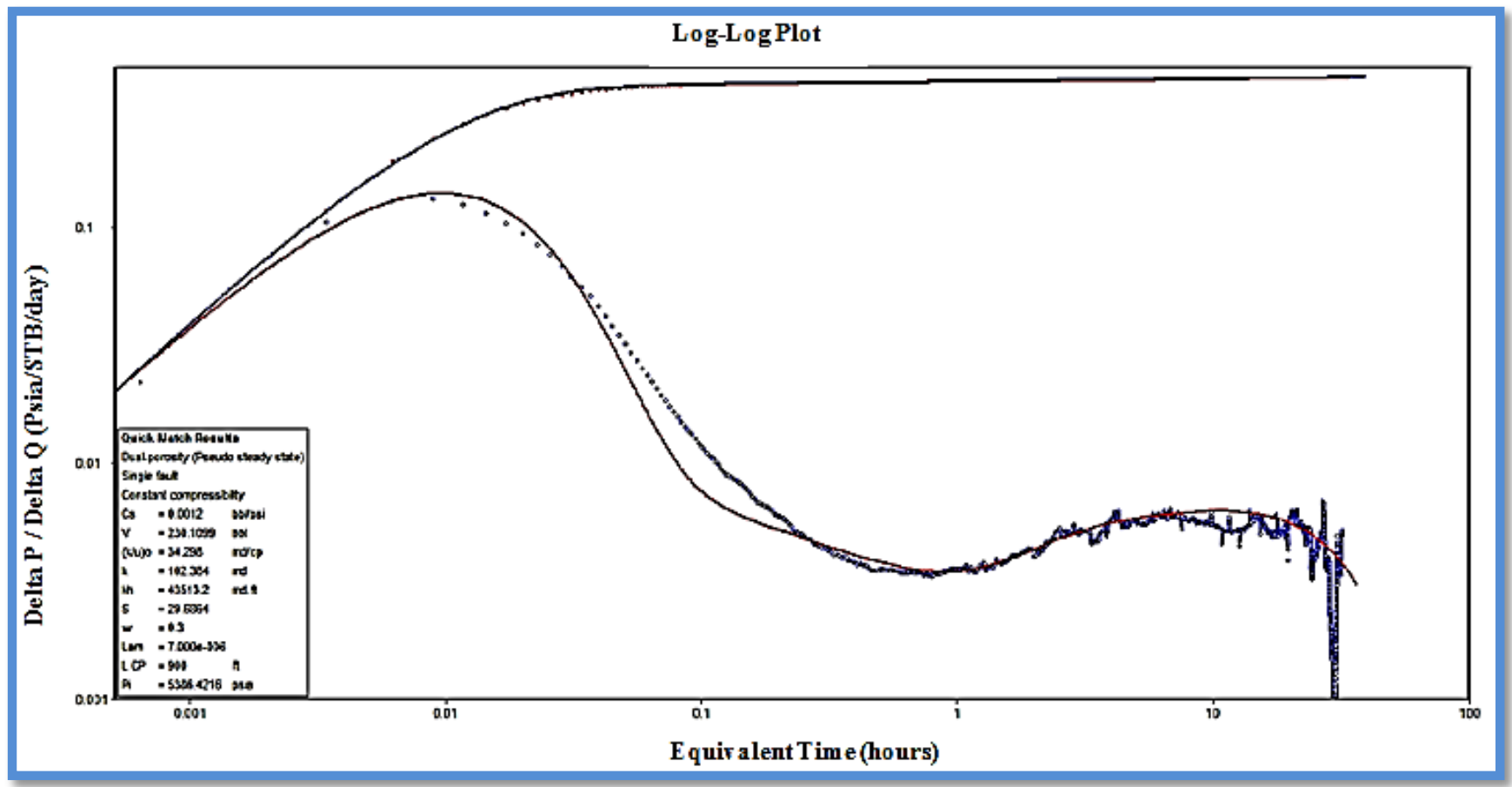

Figure 9: Log- Log diagnostic plot for the final buildup after fitting

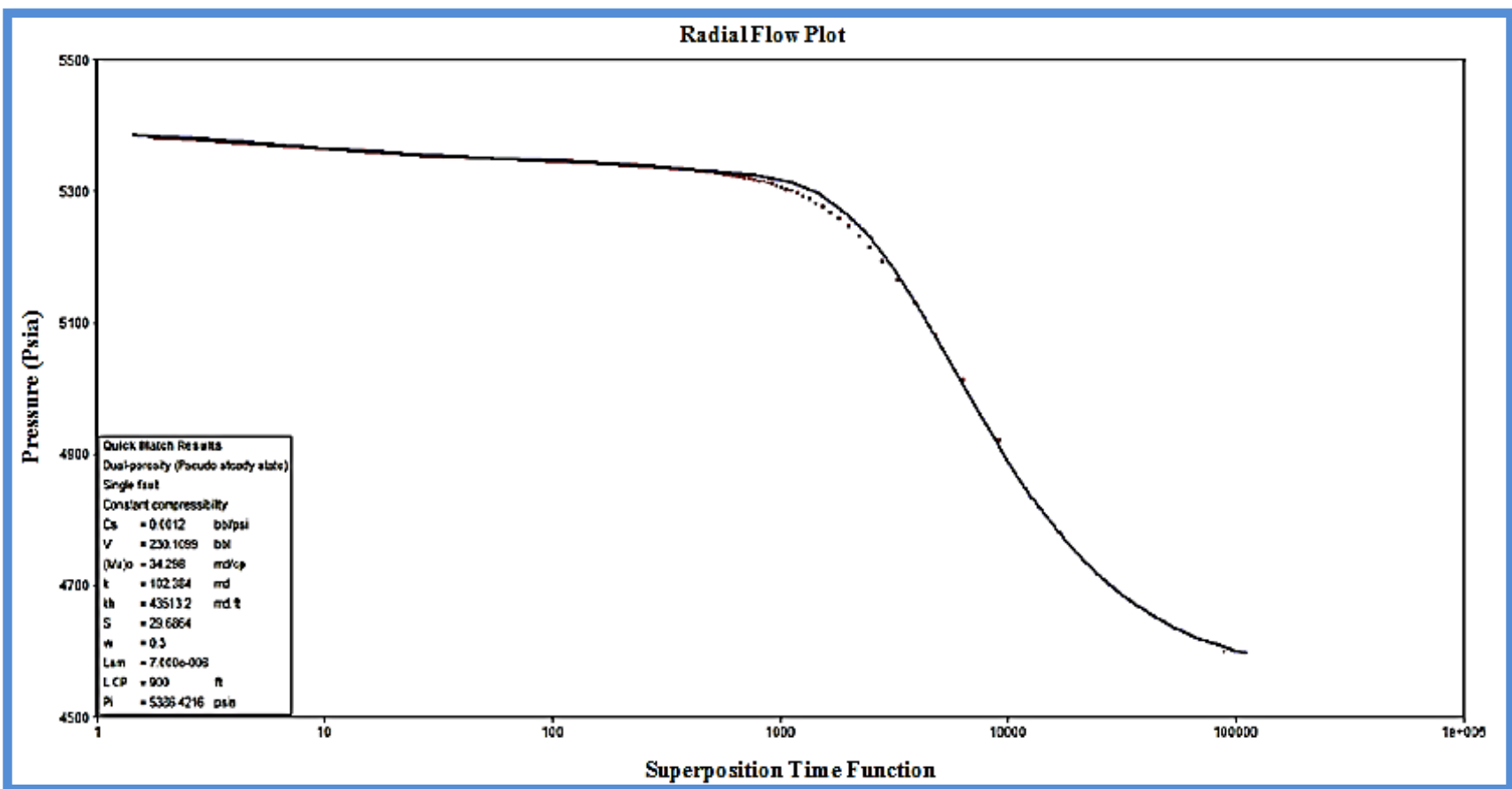

Figure 10: Semi-Log after fitting for final pressures buildup well-1 
Table 7: Results of final buildup of well-1 after fitting

\begin{tabular}{|l|c|c|}
\hline Wellbore Storage Coefficient, $(\mathrm{Cs})$ & 0.0012 & $\begin{array}{c}\mathrm{bbl} / \\
\text { day }\end{array}$ \\
\hline Horizontal Permeability, (kh) & 102.384 & $\mathrm{mD}$ \\
\hline Permeability thickness, (kh*heff) & 43513.2 & $\begin{array}{c}\mathrm{mD} \\
* \mathrm{ft}\end{array}$ \\
\hline Calculated formation pressure, $(\mathrm{Pi})$ & 5386.4216 & $\mathrm{psia}$ \\
\hline Storativity Ratio, $(\omega)$ & 0.3 & - \\
\hline Interporosity Flow Coefficient & $7 * 10^{-6}$ & $\mathrm{psi}$ \\
\hline & & \\
\hline Skin factor & 29.6864 & - \\
\hline
\end{tabular}

The second model that has applied in the calculation is:

- Wellbore storage mode: Constant wellbore storage \& skin,

- $\quad$ Flow model: dual porosity (pseudo steady state).

- $\quad$ Reservoir boundary model: Infinite acting.

Although the last part of the derivative curve is not very clear, it can be estimated that the boundary model acts as infinite because the curve response for last section in derivative pressure curve is quite stable. Figure 11 clearly show Log -Log diagnostic plot after matching for infinite acting reservoir model.
Table 8: Results of the evaluation by infinite acting model

\begin{tabular}{|l|c|c|}
\hline $\begin{array}{l}\text { Wellbore Storage Coefficient, } \\
(\mathrm{Cs})\end{array}$ & 0.0013 & $\mathrm{bbl} / \mathrm{psi}$ \\
\hline Horizontal Permeability, (kh) & 102.404 & $\mathrm{mD}$ \\
\hline $\begin{array}{l}\text { Permeability thickness, } \\
(\mathrm{kh} \text { *heff })\end{array}$ & 43513.2 & $\mathrm{mD} * \mathrm{ft}$ \\
\hline $\begin{array}{l}\text { Calculated formation pressure, } \\
(\mathrm{Pi})\end{array}$ & 5389.0783 & $\mathrm{psia}$ \\
\hline Storativity Ratio, $(\omega)$ & 0.3 & - \\
\hline Interporosity Flow Coefficient & $7.558^{*} 10^{-6}$ & - \\
\hline Skin factor & 29.6793 & - \\
\hline
\end{tabular}

Figure 12 shows the line fitting and it can be seen that the calculated pressures excellently fit the measured pressure points for infinite acting reservoir model.

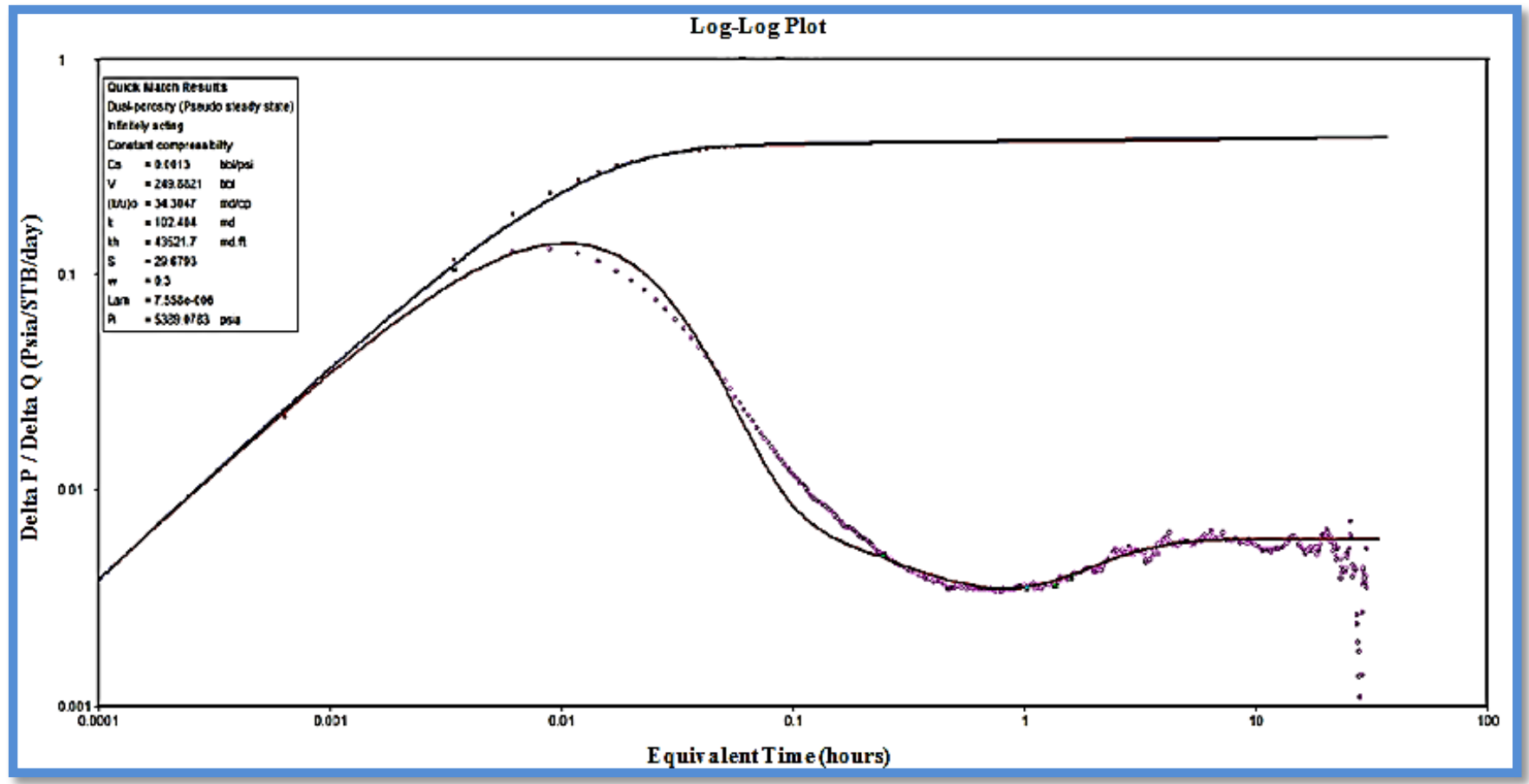

Figure 11: Log -Log diagnostic plot after matching for infinite acting model of well-1

In table 8 the result of the fitted lines for the infinitely acting boundary model is presented. No indications of the presence of boundary limit can be seen on either the figure 11: Log-Log plot or figure 12: semi-log plot. The radius of investigation was determined from the last measurement point of the buildup pressure test. It can be concluded that the boundary is not located within a radius of $2254 \mathrm{ft}$. 


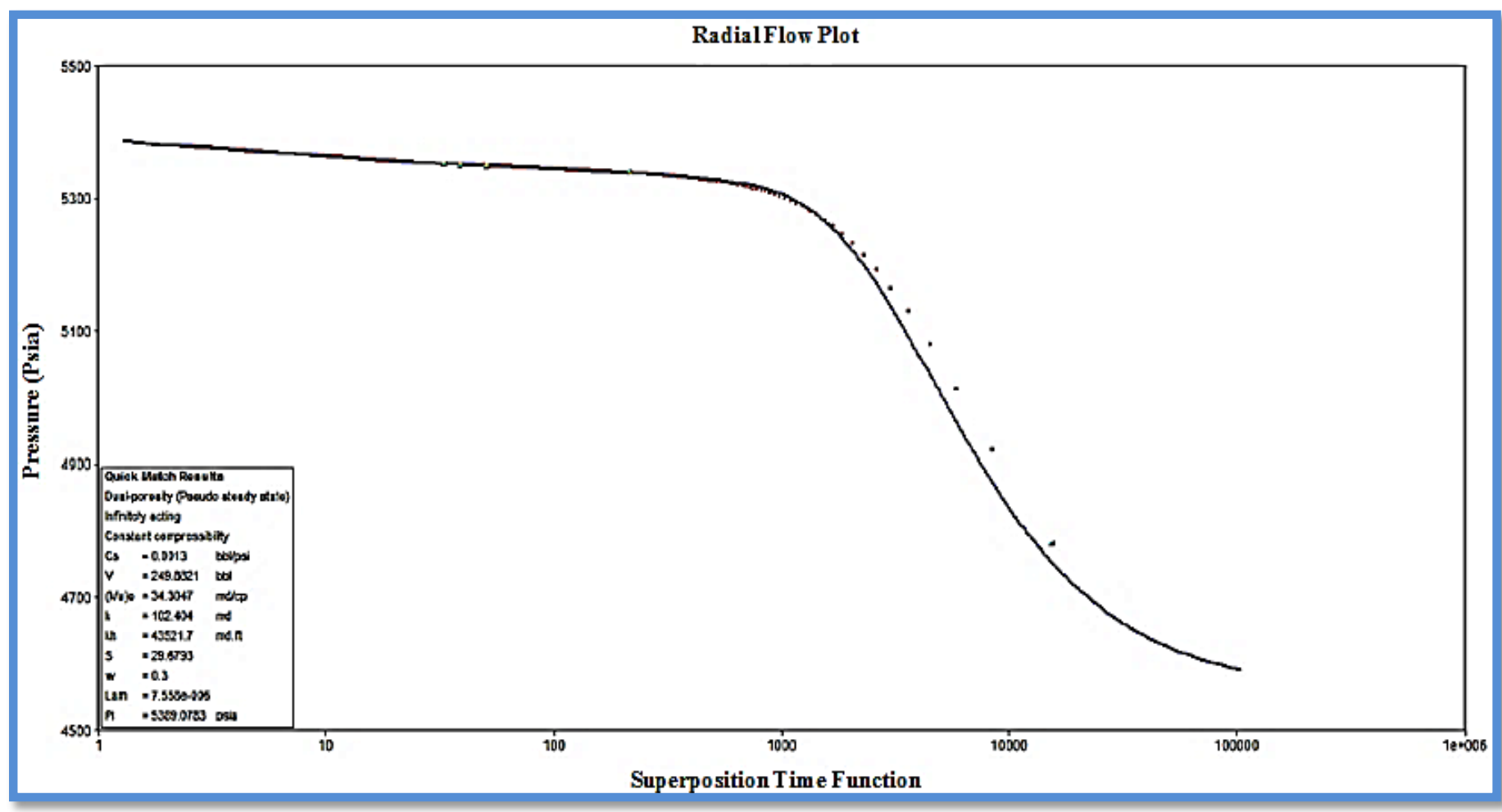

Figure 12: Semi-Log diagnostic plot after matching infinite acting model well-1

To sum up, it can be said that the final buildup pressure of well-1 was reliably evaluated. The most important parameters of the four kinds of evaluating methods are shown in table 9.

Table 9: Result of evaluation for different model for well-1

\begin{tabular}{|c|c|c|c|c|}
\hline $\begin{array}{l}\text { Parameter } \\
\mathrm{S}\end{array}$ & $\begin{array}{l}\text { Log-Log } \\
\text { Plot }\end{array}$ & $\begin{array}{l}\text { Semi- } \\
\text { Log } \\
\text { Plot }\end{array}$ & $\begin{array}{l}\text { Dual } \\
\text { porosity } \\
\text { constant } \\
\text { pres-sure } \\
\text { boundary } \\
\text { model }\end{array}$ & $\begin{array}{l}\text { Dual } \\
\text { porosity } \\
\text { infinitel } \\
y \text { acting } \\
\text { model }\end{array}$ \\
\hline $\begin{array}{l}\text { Horizontal } \\
\text { Permeabilit } \\
\mathrm{y},(\mathrm{kh}) \mathrm{mD}\end{array}$ & 107.5249 & $\begin{array}{l}105.1 \\
993\end{array}$ & 102.384 & $\begin{array}{l}102.40 \\
4\end{array}$ \\
\hline Skin factor & 31.491 & $\begin{array}{l}30.67 \\
24\end{array}$ & 29.6864 & $\begin{array}{l}29.679 \\
3\end{array}$ \\
\hline $\begin{array}{l}\text { Storativity } \\
\text { Ratio, }(\omega)\end{array}$ & & & 0.3 & 0.3 \\
\hline $\begin{array}{l}\text { Calculated } \\
\text { formation } \\
\text { pressure, } \\
\text { (Pi)psia }\end{array}$ & & $\begin{array}{l}5389 . \\
5798\end{array}$ & $\begin{array}{l}5386.421 \\
6\end{array}$ & $\begin{array}{l}5389.0 \\
783\end{array}$ \\
\hline $\begin{array}{l}\text { Interporosit } \\
\text { y Flow } \\
\text { Coeffi- } \\
\text { cient }\end{array}$ & & & $7 * 10^{-6}$ & $\begin{array}{l}7.558 * \\
10^{-6}\end{array}$ \\
\hline $\begin{array}{l}\text { Well bore } \\
\text { storage(bbl/ } \\
\text { psi) }\end{array}$ & 0.0016 & & 0.0012 & 0.0013 \\
\hline $\begin{array}{l}\text { Radius of } \\
\text { investigatio } \\
\mathrm{n},\left(\mathrm{r}_{\text {inv }}\right)\end{array}$ & & $\begin{array}{l}>2254 \\
.4819\end{array}$ & & \\
\hline
\end{tabular}

\section{DISCUSSION:}

The measurement results of the last section of the buildup pressure are more reliable and more stable than the other buildup sections. As the final buildup fitting model results seem to be the best the results of this section should be used in the future.

The results show that the system radial flow permeability, which contains both fissure and matrix, has a value of $102 \mathrm{mD}$ However; It is evaluated that $102 \mathrm{mD}$ more reliable value because it is calculated by both chosen models.

As far as skin factor values are concerned, generally the dual porosity fractured limestone reservoirs are characterized by negative skin factor. The evaluation of the final build up test of well -1 presented a positive skin factor value and the One of the reasons for this is the partial penetration. It means that only a part of the formation is open to flow at the wellbore, so we have to calculate with Flow Convergence, which is responsible for the pressure loss. The other reason is the damage caused by mud while drilling, but this part of the skin disappeared while the well was being cleaned up.

The Storativity Ratio, $(\omega)$ has the same value $(0.3)$ in both (dual porosity, constant pressure boundary) and (dual porosity infinitely acting) models.it is a significant value. In naturally fractured reservoirs, $\varphi_{\mathrm{f}}$ is usually very small, due to it $\omega$ is commonly less than 0.1 .

The interporosity flow coefficient in both (dual porosity, constant pressure boundary) and (dual porosity infinitely acting) models showed up the values from $7 * 10^{-6}$ and $7.558 * 10^{-6}$ respectively. Although there is a slight difference between the values we can say that they are approximately the same.

For calculated formation pressure the results vary between 5386 psia to5389 psia. However, I find the 5389 
psia is more reliable value because it was achieved in both chosen models.

\section{CONCLUSION}

1. Using well test analysis software such as pan system would help in saving time, improving work, precise result and giving multi options for calculation and plotting techniques as well as simulation models to apply to the test interpretation.

2. To conduct a good well test it is essential to have a perfect well testing design, accurate installation, precise monitoring of the pressure measurement tools and flow rate recorders while running into the well, recording data during the entire well testing events, try to obtain a neat data output and minimize any gauge misleading data that might lead to wrong judgments by the evaluator.

3. The interpretation in most cases is a judgment of engineer to decide which model is suitable, figure on, Petrophysical, geological, reservoir data and mathematical formulation is used to make a model for the reservoir characteristics, reservoir parameters and predication for future can be achieved with this model.

4. Well bore storage has an excessive effect on obscuring reservoir characteristic during evaluation. It disguises the reservoir response until late time of the test and it has a major nuisance to well test interpretation.

5. Although the first buildup and second buildup are interpreted, the only reliable and dependable reservoir parameters are obtained from final buildup. So that, calculated parameters in final buildup could be used for future predictions and calculations.

6. In well test evaluation of well-1, the boundary was not able to be clearly seen due to insufficient test end time to reveal the pressure response affected by reservoir boundary.

7. It was able for $b$ tested Well-1 with the result of the final build up evaluation to find the flow parameters of dual porosity reservoir in the vicinity of well. As the storativity ratio between the matrix and the fissures was $\omega=0.3$ while the (interporosity coefficient) which characterizes the flow between the fissures and the matrix was $\lambda=7.558 * 10-6$.

8. Due to a significant wellbore storage effect and the phase segregation effect during the evaluation of the pressure buildup curves, fissure radial flow which characterizes flow from the fissures to the well was latent. Therefore, in all of the cases, the permeability of the fissures could not be determined correctly.

9. The permeability was valid for the matrix and the fissure together, the value around $102 \mathrm{mD}$.
10. Despite the fact that the double porosity limestone reservoirs usually have negative skin, for both of well tests, positive, medium magnitude skin factor could be determined. Considering the literature review available, it is realized that the positive skin factors can be resulted of either the partial penetration skin effect or formation damage due to mud filtration.

11. Based on analyzed skin factor workover need to be done to calculate this problem and increasing productivity index in the future.

\section{REFERENCE}

[1] A.C. Gringarten, "Interpretation of Tests in Fissured and Multilayered Reservoirs with Double-Porosity Behavior: Theory and Practice," J. Pet. Tech., vol. 36 no. 4, pp. 549-564. Apr. 1984.

[2] A.C. Gringarten, "How To Recognize "DoublePorosity" Systems From Well Tests". J. Pet. Tech., vol. 39 no. 6, pp. 631-633. Jul. 1987.

[3] A. I. Mohammad, A.S.M. Woobaidullah and I. Badrul, "ANALYSIS OF DST TO PREDICT OIL SAND: A CASE STUDY OF KAILASHTILLA FIELD” Bangladesh J. Sci. Res. Vol. 29 no. 1, pp. 19-29 June, 2016.

[4] B. England, "Introduction to well testing", $1^{\text {st }}$ ed. Venezuela, USA: Shlumberger Wireline and testing, 1998, sec. (3-6).

[5] C. Robert and J. Earlougher: "Advances in Well Test Analysis". $2^{\text {ed }}$ ed., New York, Dallas, SPE, 1977, Ch. 8, pp. 90-120.

[6] D. Bourdett, "Well test analysis: the use of advanced interpretation", $1^{\text {st }}$ ed. Paris, France, Elsevier Science B. V., 2002, pp.90-150.

[7] G. Bourdarot, "Well testing Interpretation Methods", $2^{\text {ed }}$ ed. Paris, France SPE, 1998, pp. 143170.

[8] H. Cinco, and F. Samaniego, "Transient pressure analysis for fractured wells", J. Pet. Tech., vol. 33 no. 9, Sep. 1981.

[9] H.J. Ramey Jr: "Advances in Practical Well-Test Analysis", J. Pet. Tech., vol. 44 no. 6, Jun. 1992.

[10] W. Hurst, "Establishment of the Skin Effect and Its Impediment to Fluid into a Well Bore," Pet. Eng. pp. 6-16, Oct. 1953.

[11] J. Lee, "Well Testing". $1^{\text {st }}$ ed. New York, Dallas, SPE, 1982.

[12] J.E. Warren, and P.J. Root, "The Behavior of Naturally Fractured Reservoirs", J. Pet. Tech. vol. 3 no. 3, pp. 245-255. June. 1963.

[13] K. Serra, A.C. Reynolds, and, R. Raghavan, "New Pressure Transient Analysis Methods for Naturally Fractured Reservoirs" J Pet Techno, vol. 35, no. 12, pp. 2271-2283, May. 1983.

[14] L.G. Jones, and J.W. Watts, "Estimating Skin Effect in a Partially Completed Damaged Well," J. Pet. Tech. vol. 23 no. 2, pp. 249-252, Feb.1971.

[15] M. Muskat, "Partially Penetrating Wells in Isotropic Formations", Potential Distribution, Physics, vol. 329 no. 2, pp. 12-20, J. 1932. 
[16]O. A. De Swan, "Analytical Solutions for Determining Naturally Fractured Reservoir Properties by Well Testing," J. Pet. Tech., vol. 16 no. 3, pp. 117-122. Jun, 1976.

[17]R. N. Horne, "Modern well test Analysis (A computer Aided Approach)", $4^{\text {th }}$ ed. Palo Alto, California: Petro way, Inc, 1990.

[18] W. Marshall Black, "A Review of Drill-Stem Testing Techniques and Analysis", J. Pet. Tech, vol. 8 no. 6, June 1956.

\section{ACKNOWLEDGMENTS}

Here, it is need to send our thankfulness to those martyrs who sacrificed with their blood for protecting Kurdish nation and Kurdistan and to the Peshmarga forces that are defending Kurdistan against terrorists. We also thank all of our friends to help us to adapt the data for interpretation and solving problems during data analyzing and using software.

\section{Biography}

\subsection{Biography of the first author}

My name is Zheno Kareem Ahmed; I have master degree and bachelor in Petroleum Engineering. I got bachelor in Koya University in Kurdistan and Master of Sciences in Teesside University in the UK. I currently have assistance lecture position in Petroleum and Energy Department in College of technical Engineering in Sulaimani Polytechnic University-Sulaimani-Iraq: here is my Google scholar account:

https://scholar.google.com/citations?hl=en\&user=pTWb 9vgAAAAJ\&view op=list_works\&gmla=AJsNF6rlTIR6olldSGHs0keJEwT1J8Tgvp54rfS5sEPmbgo8i5QTt6GqJ C3cxM C60cKuvcbcaTU0kh_K_gcVU4WJ1HJ5cTw

\subsection{Biography of the second author}

My name is Halkawt Ismail M-Amin; I have master degree in Banking and Finance and bachelor in Accounting. I got bachelor in Sulaimani University in Kurdistan and Master of Sciences in Nearest University in Cyprus. I currently have head of department position in bank administration department in Dukan technical Institute in Sulaimani Polytechnic University-SulaimaniIraq: here is my Google scholar account: https://sites.google.com/a/spu.edu.iq/halkawt-amin/ 